\title{
Transsituational negative contrast
}

\author{
CHARLES F. FLAHERTY and ALEXANDRA AVDZEJ \\ Busch Campus, Rutgers University, New Brunswick, New Jersey 08903
}

\begin{abstract}
Rats were shifted from $32 \%$ sucrose solution in one apparatus to a $4 \%$ sucrose solution in a different apparatus, and the performance of these animals was compared to rats that received the $4 \%$ solution in both situations. Transsituational negative contrast effects were found in both consummatory and instrumental measures of behavior and, in addition, these contrast effects were found to have some elements in common with both successive and simultaneous contrast effects, but were identical to neither.
\end{abstract}

The performance of an animal shifted from a large to a small reward generally suffers in comparison to animals that have had no prior experience with the large reward. This decrement in performance, termed a negative contrast effect, has been found in a wide variety of experimental situations and with a variety of rewards. For example, contrast has been obtained in runways with shifts in amount of food (e.g., Crespi, 1942, DiLollo \& Beez, 1966), in complex mazes with shifts to qualititatively different foods (e.g., Elliott, 1928), in free-operant paradigms with shifts in schedule of reinforcement (e.g., Reynolds \& Limpo, 1968), and in simple consummatory response situations in which the shift has been to a lower concentration of sucrose solution (e.g., Flaherty, Capobianco, \& Hamilton, 1973; Vogel, Mikulka, \& Spear, 1968).

The occurrence of a contrast effect implies that the animal is, in some sense, comparing the new reward with the old, and the outcome of this comparison influences the animal's behavior. One question of interest that arises concerning contrast effects relates to the conditions under which this comparison will be made. Specifically, will a contrast effect occur if a shift in experimental situation is made concurrently with a shift in reward, or will reward comparisons be restricted to a given stimulus environment? Premack (1969) attempted to investigate this problem by comparing the performance of rats repeatedly shifted from a situation in which running in a wheel was reinforced by the opportunity to drink milk on a mult VI, VI schedule to a situation in which barpressing on an FR schedule was reinforced with milk. In two of the three rats tested, Premack found evidence that decreases in reinforcement frequency in the running wheel led to increased rates of responding on the FR schedule. In other words, 2 of the 3 animals showed a behavioral contrast effect that was transsituational. In the present experiment, we investigated the influence of stimulus context on reward contrast by varying reward quality (shifting rats from a high- to a low-concentration sucrose solution)

This research was supported by a grant from the Rutgers research council and by Grant $M H-24612$ from the National Institute of Mental Health. Portions of these data were presented at the 1975 meetings of the Eastern Psychological Association. Reprint requests should be sent to Charles Flaherty, Psych ology Department, Busch Campus, Rutgers University, New Brunswick, New Jersey 08903. concurrently with a shift from one experimental task to another. Specifically, some rats were repeatedly shifted from a Plexiglas chamber in which sucrose solutions were made freely available to a standard runway in which the sucrose solutions were available in the goalbox. Other rats were shifted in the opposite direction, that is, they had their first daily experience in the runway and were then shifted to the consummatory situation. Control animals received the same (low) concentrations of sucrose in both apparatuses.

\section{METHOD}

Subjects. Twenty-four experimentally naive male rats of the Sprague-Dawley strain were used as subjects. The rats were reduced to $82 \%$ of their free-feeding weight.

Apparatus. The apparatus consisted of a straight runway, $10.2 \mathrm{~cm}$ wide and high, with a $36.7-\mathrm{cm}$ startbox, $172.1-\mathrm{cm}$ alley, and $34.8-\mathrm{cm}$ goalbox. The startbox was gray and separated from the rest of the runway by a gray guillotine door. The alley and goalbox were black. A clear Plexiglas door separated the alley and goal sections of the runway and a clear Plexiglas lid covered the runway. Hunter photorelays and Standard electric timers provided for measurement of start, run, and goal times. Start time was measured from the opening of the startbox door to Photobeam 1 located $15.2 \mathrm{~cm}$ beyond the door. Run time was from Photobeam 1 to Photobeam 2 located $125.7 \mathrm{~cm}$ further down the alley, and goal time was measured from Photobeam 2 to Photobeam 3, which was $58.4 \mathrm{~cm}$ away and $8.9 \mathrm{~cm}$ from the end of the runway. The sucrose solution was presented in a graduated cylinder with a drinking spout accessible through a hole located in the end of the goalbox. The drinking tube was mounted on a cam-operated magazine which, with associated relay programming equipment, could be used to present or retract the tube from the drinking position.

The second apparatus (a consummatory apparatus) was a Plexiglas chamber measuring $30 \times 25 \times 25 \mathrm{~cm}$. A graduated cylinder containing the sucrose solution was presented through a hole in one side of the chamber. The cylinder was mounted so that the orifice of the glass drinking spout was centered in the hole and flush with the outside wall of the chamber when in the drinking position. The availability of the tube in the position was signaled by the onset of a pilot light. In both testing situations, one side of a contact relay circuit was connected to the wire mesh floor and the other side of the circuit was connected to a wire immersed in the solution contained in each bottle. In both the runway and the consummatory apparatus the number of licks made in each 1-min access period to the sucrose solution was measured. In the consummatory apparatus, the latency of the first lick also was measured.

Procedure. Four groups of six rats each were run. Group $32 \mathrm{R}-4 \mathrm{C}$ first received two trials with the $32 \%$ sucrose solution in the , unway and then two $1-\mathrm{min}$ access periods to the $4 \%$ in the 

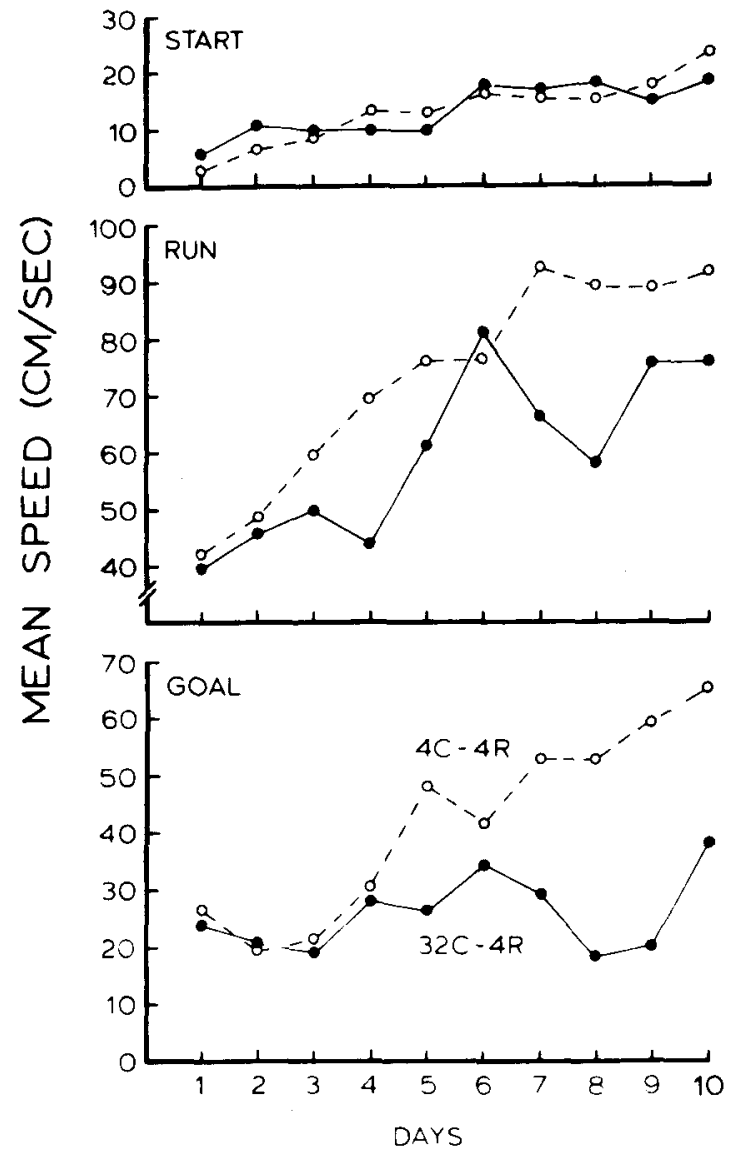

Figure 1. Mean start, run, and goal speeds as a function of training days and sucrose conditions. The 32C-4R group was shifted from $32 \%$ in the consummatory apparatus to $4 \%$ in the runway; the $4 \mathrm{C}-4 \mathrm{R}$ group received $4 \%$ in both situations.

consummatory apparatus. Group $4 \mathrm{R}-4 \mathrm{C}$ received $4 \%$ in the runway and then $4 \%$ in the consummatory apparatus. Conversely, Group $32 \mathrm{C}-4 \mathrm{R}$ was tested first in the consummatory apparatus, receiving $32 \%$ there and then receiving $4 \%$ solution in the runway. Group $4 \mathrm{C}-4 \mathrm{R}$ received $4 \%$ in the consummatory apparatus and $4 \%$ in the runway. On 2 pretraining days the rats were allowed to explore the runway and the consummatory apparatus for $5 \mathrm{~min}$ each on both days. On the second day of pretraining, the rats were given experience with sucrose in the runway goalbox and in the consummatory apparatus. Three days prior to that, the rats had been given $2 \mathrm{ml}$ of sucrose solution in their home cage. The unshifted rats (4-4) were given a $4 \%$ sucrose solution and the shifted rats $(32-4)$ were given a $16 \%$ solution. All groups received 10 days of training with two trials per day in each apparatus and with a $2-\mathrm{min}$ intertrial interval.

Testing for Groups $32 \mathrm{R}-4 \mathrm{C}$ and $4 \mathrm{R}-4 \mathrm{C}$ was conducted in the following manner: At the start of each trial, the rat was placed in the startbox facing away from the door and the door was immediately raised. Upon reaching the goalbox, the rat had access to the sucrose solution for one minute starting with the first lick. After two trials in the runway, the rat was taken in a carrying box to another room and placed in the consummatory apparatus in the corner farthest from the tube. Latency of licking was recorded. The rats again had access to the solution for 1 min beginning with the first lick, after which the tube was withdrawn and reinserted 2 min later for a second 1 -min trial. The procedure was the same for Groups $32 C-4 R$ and $4 C-4 R$ except those subjects were tested in the consummatory apparatus first and then in the runway. The running order of the groups and the subjects within the groups was randomized. The experiment was carried out in two complete replications, each with 3 rats per cell.

\section{RESULTS}

Start, run, and goal times in the runway were converted to speeds $(\mathrm{cm} / \mathrm{sec})$ for analysis. Results obtained for Groups $32 \mathrm{C}-4 \mathrm{R}$ and $4 \mathrm{C}-4 \mathrm{R}$ in the runway are presented in Figure 1. No reliable differences between groups were found in start or run speed, but a large contrast effect was found in the goal speed measure. It is apparent in Figure 1 that the group shifted from $32 \%$ in the consummatory apparatus to $4 \%$ in the runway ran considerably slower in the goal region than the unshifted groups $(F=6.56, \mathrm{df}=1 / 10, \mathrm{p}<0.03)$. The lick-rate data for these animals are presented in the top panel of Figure 2. It is apparent that the shifted animals licked considerably less of the $4 \%$ solution than the unshifted animals $(F=33.78$, df $=1 / 10$, $\mathrm{p}<.0003$ ). Thus, the pattern of results obtained in the animals shifted from the consummatory to the runway apparatus was the following: large and immediate

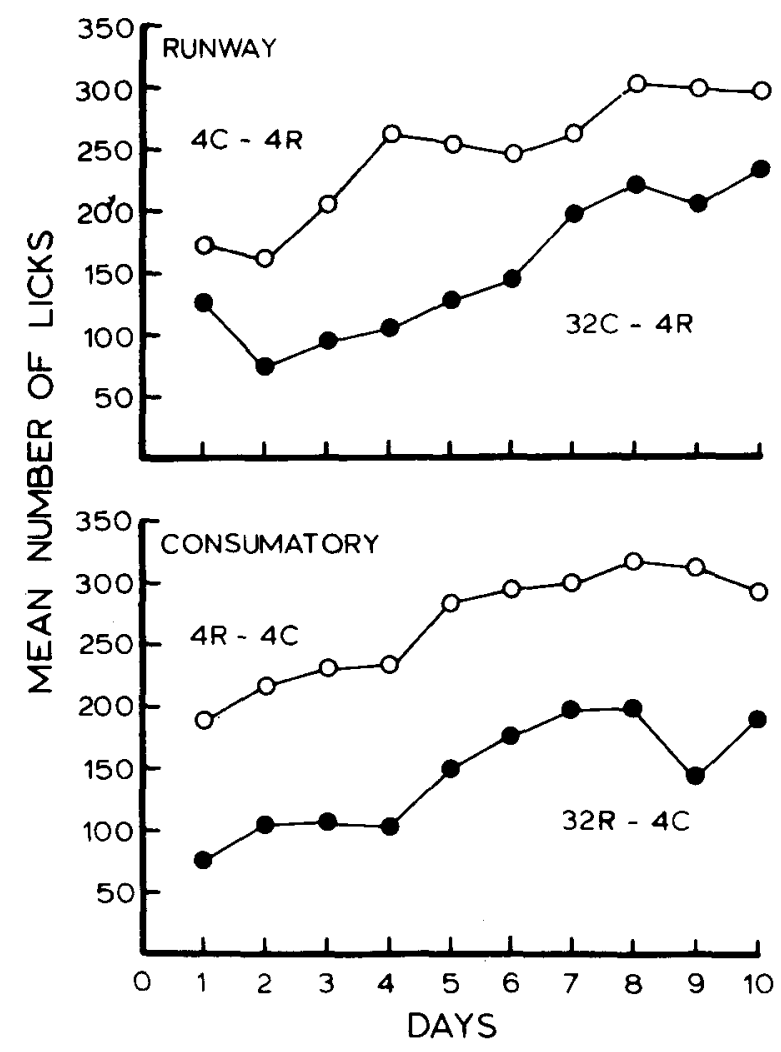

Figure 2. Mean licks per minute as a function of training conditions. The top panel depicts data obtained in the runway following differential experience in the consummatory apparatus; the bottom panel depicts data obtained in the consummatory apparatus following experience in the runway. 
contrast in the lick-rate measure, reliable and gradually developing contrast in goal speed, arithmetic but not reliable contrast developing late in the run speed, and no indication of contrast in the start speed.

The runway measures obtained with the animals that received their first experience in the runway each day showed that the start, run, and goal speeds were reliably faster for the animals receiving the $32 \%$ sucrose solution (start speed $\mathrm{F}=4.56, \mathrm{df}=1 / 10, \mathrm{p}<.06$; run speed $F=5.97, \mathrm{df}=1 / 10, p<.04$; goal speed $F=8.01$, $\mathrm{df}=1 / 10, \mathrm{p}<.02$ ). However, a higher lick rate obtained with the $32 \%$ animals was not reliably different from the lick-rate measures of the $4 \%$ animals $(F=2.58$, $\mathrm{df}=1 / 10, \mathrm{p}>.10$ ).

The lick-rate data for those rats in the consummatory apparatus are presented in the bottom panel of Figure 2. Again, it is evident the group shifted from $32 \%$ to $4 \%$ licked the $4 \%$ at a lower rate than the group receiving only $4 \%(F=19.06, \mathrm{df}=1 / 10, \mathrm{p}<0.002)$. Contrast was present from the first day of the test period. It is also apparent in Figure 2 that the performance of the runway response prior to receiving the sucrose solution did not appreciably alter the size of the contrast obtained with the lick-rate data. A statistical comparison of the size of the contrast effects obtained in the two apparatus yielded no reliable differences $(F<1.00)$.

In the animals switched from runway to consummatory apparatus there was a difference in the lick latency in the direction of longer latencies for those rats shifted from $32 \%$ to $4 \%$ compared to those consistently receiv. ing $4 \%$, but this difference was not statistically reliable.

\section{DISCUSSION}

The present results show that negative contrast effects will occur in a transsituational paradigm, at least one in which a consummatory response is required in one stimulus context and an instrumental response in the other. Contrast effects developed rapidly in both experimental conditions and the size of the contrast effect as measured by lick-rate, the only response in common between the two situations, was uninfluenced by the testing apparatus. In the runway apparatus, the contrast effect was found in both the consummatory response and one measure of instrumental behavior, goal-speed. In the consummatory apparatus contrast occurred in lick-rate only. Licking latency showed a tendency in the direction of contrast, but the effects were not statistically reliable.

Several aspects of these results deserve comment. First of all, these results are relevant to the boundary conditions of contrast in that they indicate that rats will readily compare sucrose concentrations received in two different situations and, in particular, the results show that performance in an instrumental task will be ad. versely affected if the sucrose solution received there is less preferred than the sucrose solution received in a simple consummatory situation in a different apparatus. To this extent, these results are similar to the "intertrial reinforcement" effects found with solid food rewards (e.g., Black, House, \& Moss, 1973) and raise the question of what the limits of the conditions are under which rats will compare rewards and show contrast effects. Premack's behavioral contrast experiment (Premack, 1969) indicates that the conditions might be quite varied indeed.

The results of this experiment also provide information concerning the conditions sufficient to produce contrast in the runway with shifts in sucrose solutions. There are a large number of experiments that have shown no successive negative contrast effects when sucrose concentrations were shifted in the runway (e.g., Collier, Knarr, \& Marx, 1961; Flaherty, Riley, \& Spear, 1973; Goodrich \& Zaretsky, 1962; Rosen \& Ison, 1965; Rosen, 1966; Spear, 1965). These repeated failures to obtain contrast in the runway stand at odds with another series of experiments indicating that contrast is readily obtained when sucrose solutions are shifted in an operant barpressing task ( e.g., Marx \& Pieper, 1963; Pieper \& Marx, 1963), although in these latter experiments the shift in sucrose solutions was made concurrently with a shift from "free" magazine presentations of the sucrose to the requirement that an operant response be made prior to the presentation of the sucrose. That is, either within a daily session (Pieper \& Marx, 1963) or on alternate daily sessions (Marx \& Pieper, 1963) the rats were shifted from free access to one sucrose concentration to a barpress task that was reinforced with a different concentration. Under these conditions, reliable contrast effects were obtained in rate of barpressing. It is apparent that the present experiment is similar to these operant experiments, differing principally in the use of a runway and in the fact that the consummatory experience was given in a different apparatus. Thus, it appears that interspersing consummatory experience with instrumental experience may be sufficient to produce an instrumental contrast with sucrose solutions.

A terminological question remains as to whether these contrast effects should be considered successive or simultaneous (Spear \& Spitzner, 1966). Procedurally, the present experiment is like the typical simultaneous contrast experiment in that the animals are repeatedly shifted between sucrose solutions and there are differential stimuli correlated with the different sucrose solutions. Furthermore, the stability of the contrast is similar to that found in the simultaneous paradigm (Flaherty, Riley, \& Spear, 1973). One aspect of these data is not, however, consistent with the results of the usual simultaneous contrast experiment. In the present experiment the contrast effect was greatest in the runway and decreased to nonsignificance in the start region. This is the pattern of results obtained in the typical successive contrast paradigm (e.g., Cleland, 
Williams, \& DiLollo, 1969; Flaherty \& Kelly, 1973) and is contrary to the typical simultaneous contrast result in which the contrast is largest in the start region and decreases in size toward the goal region (e.g., Flaherty, Riley, \& Spear, 1973; Ludvigson \& Gay, 1967). Thus, the present transsituational paradigm has aspects similar to both successive and simultaneous contrasts, but is apparently not identical with either.

\section{REFERENCES}

Black, R. W., House, W.. \& Moss, J. Runway performance as a function of magnitude or runway reward and intertrial reinforcement. Psychological Reports, 1973, 52, 331-333.

Cleland, E. A., Williams, M. Y., \& DiLollo, V. Magnitude of negative contrast effect in relation to drive level. Psychonomic Science, 1969,15,121-122.

Collier, G., Knarr, F. A., \& Marx, M. H. Some relations between the intensive properties of the consummatory response and reinforcement. Journal of Experimental Psychology, 1961, 62. 484-495.

Crespi, L. P. Quantitative variation in incentive and performance in the white rat. American Journal of Psychology, 1942.55. 467-517.

DiLollo, F. D., \& Beez, V. Negative contrast effect as a function of magnitude of reward decrement. Psychonomic Science, $1966,5,99-100$

Elliott, $M$. H. The effect of change of reward on the maze performance of rats. University of California Publications in Psychology, 1928, 4, 19-30.

Flaherty, C. F., Capobianco, S., \& Hamilton, L. W. Effect of septal lesions on retention of negative contrast. Physiology and Behavior, 1973, 11, 625-631.

Flaherty, C. F.. Kelly, J. Effect of deprivation state on successive negative contrast. Bulletin of the Psychonomic Society. 1973, 1. 365-367.
Flaherty, C. F., Riley, E. P., \& Spear, N. E. Effect of sucrose concentration and goal units on runway behavior in the rat. Learning \& Motivation, 1973, 4, 163-175.

Goodrich, K. P. \& Zaretsky, H. Running speed as a function of concentration of sucrose during pretraining. Psychological Reports, $1962,11,463-468$

Ludvigson, $H$. W. \& Gay, R. A. An investigation of conditions determining contrast effects in differential reward conditioning. Journal of Experimental Psychology, 1967, 75, 37-42.

Marx, M. H. \& Pieper, W. A. Instrumental acquisition and performance on fixed interval reinforcement as a function of incentive contrast. Psychological Reports, 1963, 12, 255-258.

Pieper, W. A., \& Marx, M. H. Effects of within-session incentive contrast on instrumental acquisition and performance. Journal of Experimental Psychology, 1963, 65, 568-571.

Premack, D. On some boundary conditons of contrast. In J. T. Tapp (Ed.), Reinforcement and behavior. New York: Academic Press, 1969 , Pp. 122-145.

Reynolds, G. S.. \& Limpo, A. J. Negative contrast after prolonged discrimination maintenance. Psychonomic Science, 1968, 10, 323-324.

Rosen, A. J. Incentive-shift performance as a function of magnitude and number of sucrose rewards. Journal of Comparative and Physiological Psychology, 1966, 62, 487-490.

Rosen, A. J., \& Ison, J. R. Runway performance following changes in sucrose rewards. Psychonomic Science, 1965, 2 , 335-336.

Spear, N. E. Replication report: Absence of a successive contrast effect on instrumental running behavior after a shift in sucrose concentration. Psychological Reports, 1965, 16. 336-336.

Spear, N. E.. \& Spitzner, J. H. Simultaneous and succeasive contrast effects of reward magnitude in selective learning. Psychological Monographs, 1966,80 (10, whole No. 618).

Vogel, J. R., Mikulka, P. J., \& Spear, N. E. Effects of shifts in sucrose and saccharine concentrations on licking behavior in the rat. Journal of Comparative and Physiological Psychology, $1968,66,661-666$.

(Received for publication April 29, 1975. Accepted August 14, 1975.) 